\title{
Factors associated with rapidly repeated acute poisoning by substances of abuse: a prospective observational cohort study
}

(1) CrossMark

Odd Martin Vallersnes ${ }^{1,2^{*}} \mathbb{0}$, Dag Jacobsen ${ }^{3}$, Øivind Ekeberg ${ }^{4,5}$ and Mette Brekke ${ }^{6}$

\begin{abstract}
Objective: We have previously found that $9 \%$ of patients treated for acute poisoning by substances of abuse in a primary care emergency outpatient setting presented with a new poisoning within a week. We now identify factors associated with rapidly repeated acute poisoning by substances of abuse.

Results: In 169/1952 (9\%) cases of acute poisoning by substances of abuse included consecutively from October 2011 through September 2012 at a primary care emergency outpatient clinic in Oslo, Norway, the patient re-presented within a week with a new poisoning. Homeless patients were more likely to re-present, adjusted odds ratio (AOR) 2.0 (95\% confidence interval $(C I) 1.3-3.2, p=0.003)$, as were self-discharging patients, AOR 1.7 (95\% Cl 1.2-2.4, $p=0.007$ ), and patients with an opioid as main toxic agent, AOR $1.5(95 \% \mathrm{Cl} 1.0-2.3, p=0.028)$. There was no statistically significant association between rapid re-presentation and severe mental illness or suicidal intention.
\end{abstract}

Keywords: Poisoning, Intoxication, Alcohol, Drug abuse, Repeated poisoning, Re-presentation

\section{Introduction}

In a previous study of primary care outpatient treatment of acute poisoning by substances of abuse, we found that in $9 \%$ of the cases the patient re-presented with a new poisoning within a week [1]. This finding was not explored any further in our previous study, as our focus was on the safety of the acute patient management.

Acute poisoning is associated with excess mortality, especially among patients with substance use disorders $[2,3]$. Risk of fatal poisoning increases with increasing numbers of non-fatal poisonings $[4,5]$. Hence, the high rate of rapidly repeated acute poisoning in our previous study calls for concern. In this short report we identify factors associated with re-presenting with acute poisoning within a week following an acute poisoning by substances of abuse.

\footnotetext{
*Correspondence: o.m.vallersnes@medisin.uio.no

${ }^{1}$ Department of General Practice, University of Oslo, Oslo, Norway

Full list of author information is available at the end of the article
}

\begin{abstract}
Main text
Methods

All patients 12 years and older treated at the Oslo Accident and Emergency Outpatient Clinic (OAEOC) for an acute poisoning by substances of abuse were included consecutively from 1 October 2011 to 30 September 2012. All potential substances of abuse were included. In total, there were 3139 cases of acute poisoning. In 216 cases, the patient declined participation. We excluded 406 cases where the main toxic agent was not a substance of abuse, 174 cases where the patient did not have a Norwegian national identity number, and 391 cases where the patient was transferred to hospital, leaving 1952 included cases.

The OAEOC is the main primary care emergency outpatient clinic in Oslo. It is open at all hours and has about 200,000 consultations a year. Most patients with acute poisoning by substances of abuse in Oslo are treated at the OAEOC [6]. Other primary care emergency outpatient clinics in the area do not treat significant numbers of patients with acute poisoning. In the Norwegian emergency health care system, patients have to be seen in primary care or by ambulance services to be sent on to
\end{abstract}


hospital. Oslo, the capital city of Norway, had a population of 613,285 as per 1 January 2012 [7].

The doctor treating the patient registered information on gender, age, main toxic agent, suicidal intention, severe mental illness, self-discharge, and referral to specialist health services. Any missing information was gathered from the electronic medical records. The main toxic agent was diagnosed by the doctor treating the patient, defined as the agent considered most toxic in the doses assumed taken. We grouped main toxic agents as ethanol, opioids, stimulants, gamma-hydroxybutyrate (GHB), benzodiazepines, and others. The doctor treating the patient also assessed suicidal intention behind the poisoning, and whether there was a history of severe mental illness, defined as psychosis, bipolar disorder or severe personality disorders. Homelessness was defined as having no permanent address in the National Registry, available via the electronic medical records. Patients leaving against medical advice, without being seen by a doctor, or disappearing during treatment, were registered as self-discharging.

The main outcome measure was factors associated with re-presenting to the OAEOC or any Norwegian hospital with a new poisoning within a week following an acute poisoning by substances of abuse. Nationwide data on re-presenting to hospital were retrieved from the Norwegian Patient Register (NPR). Data on re-presenting at the OAEOC were gathered from the local electronic medical records. Patients were identified by their unique Norwegian national identity number.

Statistical analyses were done in SPSS version 25.0. We did a multiple logistic regression analysis to identify factors associated with rapidly re-presenting. The level of statistical significance was set at $\mathrm{p}<0.05$.

\section{Ethics}

The study was performed in accordance with the Helsinki declaration. It was approved by the Regional Committee South East for Medical and Health Research Ethics (REK nr 2010/1129-1) and the Oslo University Hospital Information Security and Privacy Office.

\section{Results}

In 169/1952 (9\%) cases of acute poisoning by substances of abuse, the patient re-presented within a week with a new poisoning. Homeless patients were more likely to re-present, adjusted odds ratio (AOR) 2.0 [95\% confidence interval (CI) $1.3-3.2, \mathrm{p}=0.003$ ], as were self-discharging patients, AOR 1.7 (95\% CI 1.2-2.4, $\mathrm{p}=0.007$ ), and patients with an opioid as main toxic agent, AOR 1.5 (95\% CI 1.0-2.3, $\mathrm{p}=0.028)$ (Table 1).

\section{Discussion}

The one-week repetition rate of $9 \%$ is high, compared to most studies reporting rates of about $15 \%$ with longer time frames [8]. In a study encompassing all levels of health care in Oslo in 2003, Heyerdahl et al. found the repetition rate of acute poisoning to be $30 \%$ during the first year and 10\% during the first month [9]. In that study, repetition rates were estimated per patient, while in our study the repetition was registered per case. Thus, a patient presenting with three poisonings during one week would be counted as two cases of repeated poisoning in our study, but only one repeating patient in the study by Heyerdahl et al. This might explain the unusually high repetition rate in our study. Still, we consider our method of measuring repetition to be valid, as it captures series of repetitions. Serial repetitions should be considered an ominous phenomenon, signalling an increased risk of fatal poisoning $[4,5]$. Hence, a patient rapidly re-presenting with acute poisoning should be targeted for enhanced follow-up measures.

Homeless patients were more likely to re-present with a new poisoning within a week. This is in accordance with previous studies describing associations between increased repetition rates and social deprivation $[9,10]$. Self-discharge, a known predictor of hospital readmission in general [11], was also associated with rapid re-presentation. We found opioid poisoning to be associated with increased risk of rapidly repeated poisoning, in keeping with previous studies $[9,10]$. No other associations concerning toxic agents were found, including benzodiazepine poisoning, previously found to be associated with increased risk of repetition $[9,10]$.

Surprisingly, we did not find a previous history of severe mental illness or suicidal intention at the index episode to predict rapid re-presentation, though they are well documented risk factors for repeated poisoning in general $[8,9,12]$. It could even seem that suicidal intention at the index episode was associated with a decreased risk of rapid re-presentation in our study, with an adjusted odds ratio of 0.44 . However, this decrease was not statistically significant, possibly due to small numbers. Still, the decrease may stem from improved targeting for follow-up after a suicide attempt [13].

\section{Limitations}

Our study included patients at one centre only. Though most acute poisonings by substances of abuse in Oslo are treated at the OAEOC, about 200 patients with more severe acute poisoning by substances of abuse are brought directly to hospital per year after triage by the ambulance service [1]. Furthermore, in about 700 cases per year, mainly opioid overdoses, the patient is 
Table 1 Factors associated with repeated acute poisoning by substances of abuse within 1 week-logistic regression analysis

\begin{tabular}{|c|c|c|c|c|c|c|c|c|}
\hline & \multirow{2}{*}{$\begin{array}{l}\text { Cases total } \\
\mathbf{n}\end{array}$} & \multirow{2}{*}{$\begin{array}{l}\text { Re-presentation } \\
\text { within a week } \\
\text { n (\%) }\end{array}$} & \multicolumn{3}{|l|}{ Crude } & \multicolumn{3}{|l|}{ Adjusted } \\
\hline & & & Odds ratio & $95 \% \mathrm{Cl}$ & p-value & Odds ratio & $95 \% \mathrm{Cl}$ & p-value \\
\hline \multicolumn{9}{|l|}{ Gender } \\
\hline Females & 640 & $47(7)$ & 1 & & & 1 & & \\
\hline Males & 1312 & $122(9)$ & 1.3 & $0.91-1.8$ & 0.15 & 0.97 & $0.67-1.4$ & 0.89 \\
\hline $\mathrm{Age}^{\mathrm{a}}$ & - & - & 1.03 & $1.02-1.04$ & $<0.001$ & 1.03 & $1.01-1.04$ & 0.001 \\
\hline \multicolumn{9}{|l|}{ Toxic agent at index episode } \\
\hline Ethanol & 1188 & $95(8)$ & 1 & & & 1 & & \\
\hline Opioids & 437 & $50(11)$ & 1.5 & $1.0-2.1$ & 0.032 & 1.5 & $1.0-2.3$ & 0.028 \\
\hline Stimulants & 90 & $6(7)$ & 0.82 & $0.35-1.9$ & 0.65 & 0.97 & $0.40-2.3$ & 0.94 \\
\hline $\mathrm{GHB}$ & 45 & $4(9)$ & 1.1 & $0.39-3.2$ & 0.83 & 1.4 & $0.50-4.2$ & 0.50 \\
\hline Benzodiazepines & 129 & $10(8)$ & 0.97 & $0.49-1.9$ & 0.92 & 1.4 & $0.69-3.0$ & 0.34 \\
\hline Other & 63 & $4(6)$ & 0.78 & $0.28-2.2$ & 0.64 & 1.0 & $0.36-3.0$ & 0.94 \\
\hline Suicidal intention at index episode ${ }^{b}$ & 73 & $3(4)$ & 0.44 & $0.14-1.4$ & 0.17 & 0.44 & $0.13-1.6$ & 0.21 \\
\hline Severe mental illness ${ }^{b}$ & 157 & $18(11)$ & 1.4 & $0.84-2.4$ & 0.19 & 1.6 & $0.93-2.7$ & 0.091 \\
\hline Homelessness $^{b}$ & 153 & $29(19)$ & 2.8 & $1.8-4.3$ & $<0.001$ & 2.0 & $1.3-3.2$ & 0.003 \\
\hline Self-discharged ${ }^{\mathrm{b}}$ & 324 & $46(14)$ & 2.0 & $1.4-2.9$ & $<0.001$ & 1.7 & $1.2-2.4$ & 0.007 \\
\hline Referred specialist services $^{b}$ & 235 & $12(5)$ & 0.54 & $0.29-0.98$ & 0.042 & 0.64 & $0.34-1.2$ & 0.16 \\
\hline Total & 1952 & $169(9)$ & & & & & & \\
\hline
\end{tabular}

Odds ratios adjusted for the variables in the table. Adjusted odds ratios for significant associations are shown in Italic types

Cl confidence interval, GHB gamma-hydroxybutyrate

a Continuous variable

b Reference groups were no suicidal intention at index episode, no history of severe mental illness, not being homeless, regular discharge, no referral to outpatient psychiatric and/or addiction specialist health services

left on scene after treatment by the ambulance service [14]. As we did not have access to medical records from the ambulance service, the re-presentation rate is probably underestimated in our study, especially for patients with opioid overdoses.

NPR data on patient contacts in Norwegian hospitals are probably close to complete, as reporting to the register is necessary for hospital funding. However, the reported diagnoses may be inaccurate [15].

The category of severe mental illness encompassed several different diagnoses. The categorisation was based on the information available at the time to the doctor treating the patient. Hence, the prevalence is probably underestimated. Diagnoses of toxic agents were also made by the doctor treating the patient. No toxicological laboratory analyses were done. However, the diagnoses were made in real clinical situations, and decisions of patient management were based on them.

\section{Abbreviations}

AOR: adjusted odds ratio; Cl: confidence interval; GHB: gamma-hydroxybutyrate; NPR: the Norwegian Patient Register; OAEOC: the Oslo Accident and Emergency Outpatient Clinic.
Authors' contributions

OMV, DJ, OE and MB designed the study. OMV collected and collated the data. $\mathrm{OMV}$ analysed the data with contributions from DJ, OE and MB. OMV drafted the manuscript. All authors revised the manuscript. All authors read and approved the final manuscript.

\section{Author details}

${ }^{1}$ Department of General Practice, University of Oslo, Oslo, Norway. ${ }^{2}$ Oslo Accident and Emergency Outpatient Clinic, City of Oslo Health Agency, Oslo, Norway. ${ }^{3}$ Department of Acute Medicine, Oslo University Hospital, University of Oslo, Oslo, Norway. ${ }^{4}$ Division of Mental Health and Addiction, Oslo University Hospital, Oslo, Norway. ${ }^{5}$ Department of Behavioural Sciences in Medicine, University of Oslo, Oslo, Norway. ${ }^{6}$ General Practice Research Unit (AFE), University of Oslo, Oslo, Norway.

\section{Acknowledgements}

We thank the doctors at the OAEOC for including patients and registering data, and the Norwegian Patient Register for providing data.

\section{Competing interests}

The authors declare that they have no competing interests.

\section{Availability of data and materials}

The datasets generated and analysed during the current study cannot be made openly available due to conditions set by the Regional Committee South East for Medical and Health Research Ethics prior to collecting the data. Inquiries about the data and conditions for access can be made to the corresponding author. 


\section{Consent for publication \\ Not applicable.}

\section{Ethics approval and consent to participate}

The study was approved by the Regional Committee South East for Medical and Health Research Ethics (REK nr 2010/1129-1) and the Oslo University Hospital Information Security and Privacy Office. Participation was based on informed verbal consent, documented on the data registration form by the doctor including the patient.

\section{Funding}

The study was funded by the Norwegian Research Fund for General Practice.

\section{Publisher's Note}

Springer Nature remains neutral with regard to jurisdictional claims in published maps and institutional affiliations.

Received: 16 Auqust 2018 Accepted: 9 October 2018

Published online: 12 October 2018

\section{References}

1. Vallersnes OM, Jacobsen D, Ekeberg O, Brekke M. Outpatient treatment of acute poisoning by substances of abuse: a prospective observational cohort study. Scand J Trauma Resusc Emerg Med. 2016;24:76.

2. Chesney E, Goodwin GM, Fazel S. Risks of all-cause and suicide mortality in mental disorders: a meta-review. World Psychiatry. 2014;13:153-60

3. Lund C, Bjornaas MA, Sandvik L, Ekeberg O, Jacobsen D, Hovda KE. Five-year mortality after acute poisoning treated in ambulances, an emergency outpatient clinic and hospitals in Oslo. Scand J Trauma Resusc Emerg Med. 2013;21:65.

4. Stoove MA, Dietze PM, Jolley D. Overdose deaths following previous non-fatal heroin overdose: record linkage of ambulance attendance and death registry data. Drug Alcohol Rev. 2009;28:347-52.
5. Gunnarsdottir OS, Rafnsson V. Risk of suicide and fatal drug poisoning after discharge from the emergency department: a nested case-control study. Emerg Med J. 2010;27:93-6.

6. Vallersnes OM, Jacobsen D, Ekeberg O, Brekke M. Patients presenting with acute poisoning to an outpatient emergency clinic: a one-year observational study in Oslo. Norway. BMC Emerg Med. 2015;15:18.

7. Statistics Norway. Statistisk sentralbyrå. http://www.ssb.no. Accessed 12 Jul 2014.

8. Owens D, Horrocks J, House A. Fatal and non-fatal repetition of self-harm: systematic review. Br J Psychiatry. 2002;181:193-9.

9. Heyerdahl F, Bjornaas MA, Dahl R, Hovda KE, Nore AK, Ekeberg O, et al. Repetition of acute poisoning in Oslo: 1-year prospective study. $\mathrm{Br} J$ Psychiatry. 2009;194:73-9.

10. Rafnsson SB, Oliver JJ, Elton RA, Bateman DN. Poisons admissions in Edinburgh 1981-2001: agent trends and predictors of hospital readmissions. Hum Exp Toxicol. 2007;26:49-57.

11. Garland A, Ramsey CD, Fransoo R, Olafson K, Chateau D, Yogendran $M$, et al. Rates of readmission and death associated with leaving hospital against medical advice: a population-based study. CMAJ. 2013;185:1207-14.

12. Larkin C, Di Blasi Z, Arensman E. Risk factors for repetition of self-harm: a systematic review of prospective hospital-based studies. PLOS ONE. 2014;9:e84282

13. Vallersnes OM, Jacobsen D, Ekeberg O, Brekke M. Mortality, morbidity and follow-up after acute poisoning by substances of abuse: a prospective observational cohort study. Scand J Public Health. 2018. https://doi. org/10.1177/1403494818779955.

14. Heyerdahl F, Hovda KE, Bjornaas MA, Nore AK, Figueiredo JC, Ekeberg $\mathrm{O}$, et al. Pre-hospital treatment of acute poisonings in Oslo. BMC Emerg Med. 2008;8:15

15. Muan B, Heyerdahl F, Lindas R, Prestmo A, Skjonsberg H, Berg KJ. Coding practice in fatal poisonings. Tidsskr Nor Legeforen. 2010;130:1601-5.
Ready to submit your research? Choose BMC and benefit from:

- fast, convenient online submission

- thorough peer review by experienced researchers in your field

- rapid publication on acceptance

- support for research data, including large and complex data types

- gold Open Access which fosters wider collaboration and increased citations

- maximum visibility for your research: over $100 \mathrm{M}$ website views per year

At BMC, research is always in progress.

Learn more biomedcentral.com/submissions 